\title{
Endoscopic findings of intestinal Behçet's disease complicated with toxic megacolon
}

A 73-year-old woman was admitted to our hospital because of diarrhea and inveterate oral ulcers. Upon admission, her body temperature was $38.2^{\circ} \mathrm{C}$. The abdominal examination revealed mild tenderness without guarding. Initial blood tests revealed a white blood cell count of $10500 / \mu \mathrm{L}$, hemoglobin level of $7.8 \mathrm{~g} / \mathrm{dL}, \mathrm{C}-$ reactive protein level of $21.7 \mathrm{mg} / \mathrm{dL}$, and positivity for HLA-B52. The day after admission, massive bloody stools appeared. Colonoscopy of the descending colon revealed punched-out ulcers scattered throughout the rectum up to the descending colon ( Fig. 1 a). While genital ulcers appeared after admission, skin lesions and eye inflammation were not detected. The patient was consequently diagnosed as having intestinal Behçet's disease. She was treated with mesalazine ( $3 \mathrm{~g} /$ day) but her condition worsened gradually, and therefore intravenous prednisolone pulse therapy ( $1000 \mathrm{mg} /$ day) was performed. However, bloody stools continued to appear. Second-look colonoscopy detected deep longitudinal ulcers in the transverse colon that exposed the muscular layer ( Fig.1 b). The patient was treated with infliximab $(5 \mathrm{mg} / \mathrm{kg})$ but complained 3 days later of severe abdominal pain and showed guarding in the left lower abdominal area. Computed tomography revealed a dilated transverse colon and perforation of the sigmoid colon with free air ( Fig. $\mathbf{1}$ c,d). Consequently, the patient underwent surgery ( $\bullet$ Fig. 2), but unfortunately she died of disseminated intravascular coagulation after surgery.

In Behçet's disease, while involvement of the gastrointestinal tract is relatively uncommon [1], the rate of perforation is relatively high [2,3]. However, complication of Behçet's disease with a toxic megacolon is extremely rare $[4,5]$. Nevertheless, our case indicates that we should pay attention to patients with extensive deep ulcers. While toxic megacolon occurs in ulcerative colitis, it is not a complication peculiar to ulcerative colitis as it can occur in any case of an ulcerative lesion with inflammation that penetrates the entire colonic wall, such as can occur in intestinal Behçet's disease.

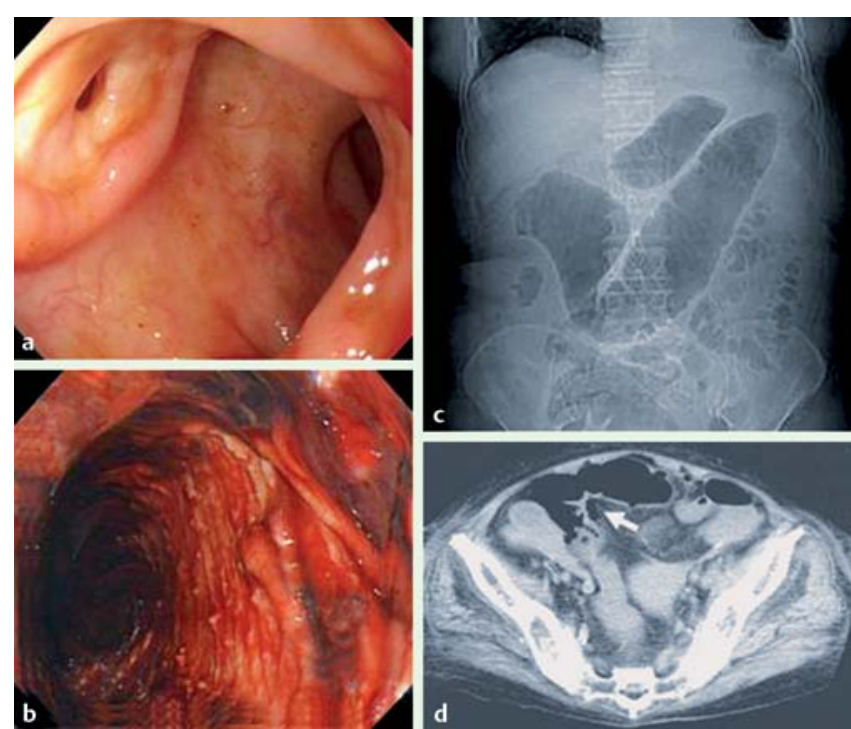

Fig. 1 a, b Endoscopic findings. a Punched-out ulcer in the descending colon. $\mathbf{b}$ Extensive deep longitudinal ulcers in the transverse colon that exposed the muscular layer. c, d Computed tomography. c Dilated transverse colon, similar to that seen in ulcerative colitis complicated with a toxic megacolon. $\mathbf{d}$ Perforation of the sigmoid colon with free air (arrow).

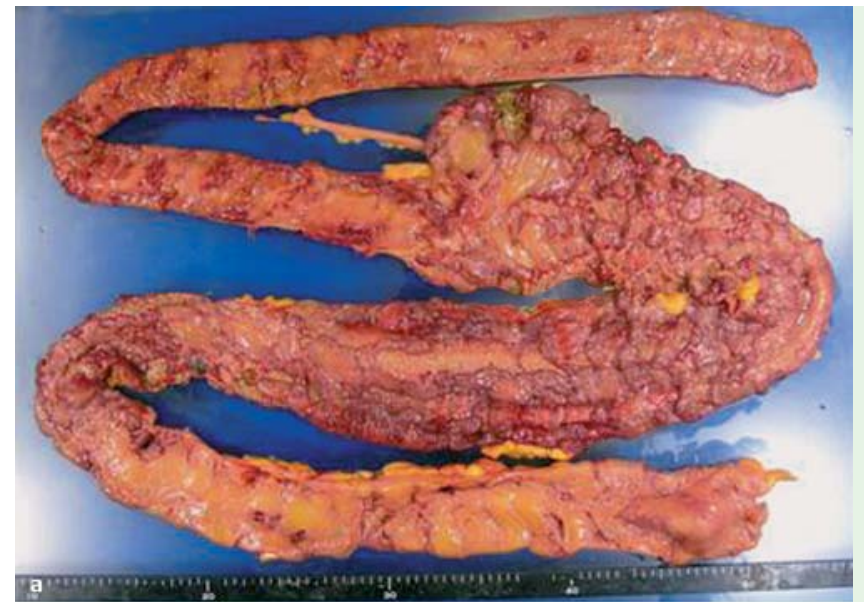

Fig. 2 a, b Surgical specimen (subtotal colectomy and ileectomy). a Multiple deep ulcers in the entire coIon and ileum. b Deep ulcer and severe infiltration of inflammation cells in the entire wall. Moreover, vasculitis and fibrinoid necrosis of the vascular wall were observed that were consistent with intestinal Behçet's disease.

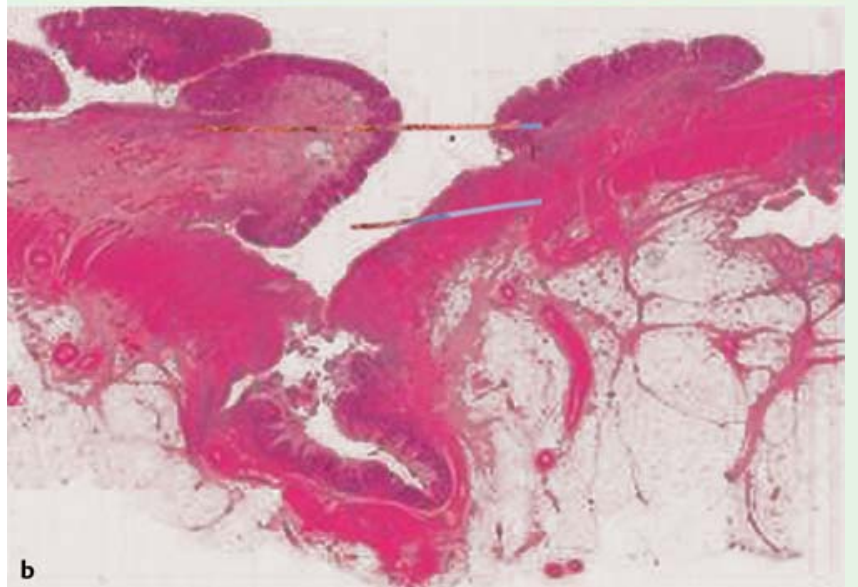




\section{Endoscopy_UCTN_Code_CCL_1AD_2AD}

Y. Umehara, M. Kudo, M. Kawasaki Division of Gastroenterology and Hepatology, Department of Internal Medicine, Kinki University School of Medicine, Osaka-Sayama, Japan

\section{References}

1 Wallace GR, Verity DH, Delamaine LJ et al. MIC-A allele profiles and HLA class I associations in Behçet's disease. Immunogenetics 1999; 49: 613-617

2 Kasahara Y, Tanaka S, Nishino M et al. Intestinal involvement in Behçet's disease: review of 136 surgical cases in the Japanese literature. Dis Colon Rectum 1981; 24: $103-106$

3 Lee CR, Kim WH, Cho YS et al. Colonoscopic findings in intestinal Behçet's disease. Inflamm Bowel Dis 2001; 7: 243-249

4 Adorian C, Khoury G, Tawil A et al. Behçet's disease complicated by toxic megacolon. Dig Dis Sci 2003; 48: 2366-2368

5 Roenspies U, Saegesser F. Behcet's disease and toxic megacolon. Schweiz Med Wochenschr 1975; 105: 99-204

\section{Bibliography}

DOI $10.1055 / \mathrm{s}-0028-1103446$

Endoscopy 2010; 42: E173-E174

(c) Georg Thieme Verlag KG Stuttgart · New York . ISSN 0013-726X

\section{Corresponding author}

\section{Kudo, MD, PhD}

Division of Gastroenterology and Hepatology Department of Internal Medicine

Kinki University School of Medicine 377-2 Ohno-Higashi

Osaka-Sayama 589-8511

Japan

Fax: +81-723-672880

m-kudo@med.kindai.ac.jp 